${ }^{2}$ Now at Department of Geology, University of Botswana, Private Bag 0022, Gaborone,

$7{ }^{3}$ School of Earth \& Geographical Sciences, The University of Western Australia, Perth, Western Australia 6009, Australia

${ }^{4}$ CSIRO Exploration \& Mining, PO Box 1130, Bentley, WA 6102, Australia

${ }^{5}$ ANKA/Inst. Synchotron Radiation, Forschungszentrum Karlsruhe GmbH, Hermannvon-Helmholtz-Platz 1, Eggenstein-Leopoldshafen, D-76344 Germany

14 Tel: 267-355-5123

15 Received........

16 accepted......... 
21 The Earth is a wet planet, where water is recycled from the mantle to the surface and back again. The mantle is generally too hot for the stability of hydrous minerals and too cold to store water within significant melt sheets. Therefore, the current paradigm in

24 geosciences is that water resides and moves only through point defects in nominally 25 anhydrous minerals such as olivine, pyroxene and garnet. We challenge this view and present the first high-resolution synchrotron images of higher dimensional defect structures within olivine $(\mathrm{Mg}, \mathrm{Fe})_{2} \mathrm{SiO}_{4}$ revealing a strong variation of water content at all length scales. Within single grains water is principally located in "wet spots" around 2-dimensional defects such as grain boundaries and cracks. These wet spots are micrometer size clouds of water, located within point defects in the olivine crystalline lattice, around 2-D defects with less than nanometre size opening. The water is not

32 found in the 2-D defects themselves. Our analysis has three major ramifications: 1) it 33 shows water rich spots around monomineralic and interphase boundaries in the 34 lithospheric mantle giving the last snapshot of fracture prior to xenolith eruption; 2) it unravels "cryptic metasomatism" as a fast fluid pathway into the lithospheric crust; 3 ) it

36 calls for a fundamental reassessment of the dynamics of water transfer within the

37 lithospheric mantle and the buoyant subduction below, suggested in the studied area.

38 Storage and transfer of water along grain boundaries within nominally anhydrous

39 minerals provides an intermediate reservoir for the dynamic planetary water cycle. 
Introduction

44 Amongst terrestrial planets the Earth appears to be the only known planet to have developed stable plate tectonics as a means to get rid of its heat. The emergence of plate tectonics out of mantle convection appears to rely intrinsically on the capacity to develop extremely weak faults in the top $100 \mathrm{~km}$ of the planet. These faults have a memory of at least several hundred millions of years. It is an open question, however, what weakens these faults, i.e. what lubricates plate tectonics. Model simulations suggest that this could be due to the effect of water on mantle rheology (Regenauer-Lieb et al., 2001). The basic underlying phenomenon was first discovered in the laboratory and dubbed hydrolytic weakening (Griggs, 1967) and commonly attributed to the existence of hydrogen in point defects. However, the exact mechanism remains obscure because point defects cannot be seen directly. Thus dynamic estimates of $\mathrm{OH}-$ defect mobility rely on atomistic computer simulation techniques (Wright and Catlow, 1994).

Such atomistic modelling was also used to investigate the transfer of water through line defects (Heggie, 1992). Heggie argued that water does not only diffuse, but it can be pumped along dislocations, enhanced through the action of deformation. Such deformation enhanced transfer of water through the lithosphere would be exactly what is needed to explain the subduction initiation paradox. It could turn an oceanic plate -

61 which is chemically a melt extraction product hence presumably of dry composition (Hirth and Kohlstedt, 1996) - locally into a wet plate, thereby bringing it close to the necessary failure condition through hydrolytic weakening (Regenauer-Lieb, 2006).

64 However, it is well known that water, on a geological time scale, cannot penetrate into the dry oceanic plate through point defect diffusion. This has clearly been shown through coupled hydrogen and temperature diffusion calculations (Regenauer-Lieb and 
67 Kohl, 2003). The paradigm of point defects as a means of diffusive water transfer may apply to the deeper mantle but it is definitely inadequate for explaining the transfer of water through the lithosphere. A direct proof of more efficient mechanism through higher dimensional defects such as creep fracture in the upper mantle (Ghandi and Ashby, 1979) or through super diffusion along dislocations (Heggie, 1992) is however lacking. This is exactly the problem we set out to analyze in this paper and we report the first direct evidence that water is controlled by 2-dimensional defects.

A principal problem with the exploration of the effect of water on higher dimensions than point defects is the inability to detect water on 2-dimensional defects such as grain boundaries and cracks. The difficulties in quantifying primary water content towards grain boundaries and cracks in natural mantle samples, such as xenoliths, are twofold. Firstly, water may be lost (or added) during entrainment in the erupting host lava, and secondly, the sensitivity and/or the spatial resolution for measuring water towards grain boundaries are insufficient with conventional methods.

We have overcome the first problem by examining interphase and monomineralic grain boundaries within the centre of olivine crystals. Fourier transformed infrared spectroscopy (FT-IR) is inherently very sensitive to structurally incorporated hydrogen, affecting the infrared spectra through the absorption intensity and wave number of hydroxyl bands. Such hydrogen incorporation is colloquially termed water. Conventional IR-microscopes have an unfavourable trade-off between the brilliance of the IR-source and the size of the analyzed spot. To overcome the second problem, measurements have been performed using the ANKA synchrotron at the Forschungszentrum Karlsruhe, Germany, which provides high-brilliance, diffractionlimited IR edge-radiation from its $2.5 \mathrm{GeV}, 200 \mathrm{~mA}$ beam. Complementary studies of 
91 the samples were performed using optical- and scanning electron microscopy, conoscopy, geothermobarometry and thermodynamic calculations.

93 Our analyses were stimulated by earlier circumstantial evidence that suggested,

94 potential of significant water storage towards grain boundaries (Hiraga et al., 2004).

95 These authors noted a strong partitioning of incompatible elements, such as $\mathrm{Ca}$ and $\mathrm{Al}$,

96 towards monomineralic grain boundaries thus indicating the passage of water. Hiraga et

97 al. postulated that a volatile-rich fluid phase or low-viscosity melt infiltrates formerly

98 fluid-free rocks and selectively dissolves and precipitates incompatible elements

99 preferentially towards grain boundaries. Moreover, direct evidence for anomalous

100 heterogeneous distribution of water in olivine has been detected using TEM methods

101 (Kishina and Wirth, 2002). Nanometre size inclusions of hydrous olivine (Mg,

$102 \mathrm{Fe}) \mathrm{SiO}_{4} \mathrm{H}_{2}$ in samples of natural mantle olivine were suggested to be formed through 103 exsolution of initially $\mathrm{OH}$ - bearing point defects. Due to the diffraction limit such

104 inclusions would be invisible for infrared methods; however, one could argue that the 105 water content could still be measured in an integrated way. On the other hand, visible 106 micrometer size inclusions are conventionally avoided by standard FT-IR 107 measurements. Consequently, their contribution to the water content in olivine is not 108 taken into account. Due to this technical limitation, there is a gap in understanding the 109 role of water in intermediate scales between the nanometre up to $0.4 \mathrm{~nm}$ and tens of 110 micrometer scale.

111 At nanometre level, indirect measurements of water mobility through point defects in 112 olivine samples are relatively well understood through a series of hydrothermal 113 annealing experiments (Kohlstedt et al., 1996; Kohlstedt and Mackwell, 1998). These 114 experiments imply that water diffusion occurs by two principal processes causing 
115 different anisotropic $\mathrm{OH}$ stretching behaviour in the IR spectra: first metastable

116 hydrogen diffusion in the presence of $\mathrm{Fe}$, followed by equilibrium diffusion of all defect

117 species for all cases (Kohlstedt and Mackwell, 1998). These diffusion mechanisms are

118 characteristic for natural olivine samples with low $a \mathrm{SiO}_{2}$ (Matveev et al., 2005;

119 Nakamura and Schmalzried, 1983) recognized by OH-stretching bands between 3430

120 and $3630 \mathrm{~cm}^{-1}$.

122 Analytical methods

123 About 150 olivine grains were handpicked and selected under a binocular microscope.

124 We selected totally inclusion-free olivine grains and olivine grains, which show

125 inclusions of Cr-spinel and/or cracks. The grains were then embedded in water free

126 epoxy resin and polished on both surfaces in parafine to avoid any contamination with

127 molecular water. The crystallographic orientation (Bxa, Bxo, or opticical normal

128 configurations) was determined by using a petrographic microscope. The thickness of

129 the analysed doubly polished sections varies between 226 and $263 \mu \mathrm{m}$. The Beer-

130 Lambert law was used to calculate the water content from the FT-IR spectra. An

131 absorption coefficient of 0.188 was used to determine the water content in forsteritic

132 olivine grains (Bell et al., 2003). The sum of all areas beneath the OH peaks in all 3

133 directions $(\alpha, \beta, \gamma)$ were added and normalized to $1 \mathrm{~cm}$.

134 We focus on cracks and mineral inclusions such as spinel. Inclusions from the centre of

135 the grains are selected. These fully embedded inclusions and cracks were selected to

136 avoid any interference from surface cracks or intersections with the polished surfaces of

137 the olivine grain. 
138 The host olivine and the fully embedded cracks and mineral inclusions were 139 investigated with FT-IR in transmitted-light mode. IR absorption spectra in the range

140 from 600 to $10000 \mathrm{~cm}^{-1}$ were acquired at the infrared beamline of the ANKA

141 synchrotron with incident light polarized along $a, b$ and $c$ axes using a Bruker IFS 66v/S

142 spectrometer coupled to an IRscopeII microscope with a 36x, 0.5 N.A. Schwarzschild

143 objective and a liquid- $\mathrm{N}_{2}$ cooled MCT detector. To check the quality of the olivine 144 samples they were measured first with the internal thermal Globar source using an 145 aperture of $50 \mu \mathrm{m}$. The spectral region of interest for this study is the $\mathrm{OH}$ stretching 146 range around $3500 \mathrm{~cm}^{-1}$. We exploited the brilliance advantage (photon flux per unit 147 source area into unit emission angle) of synchrotron light compared to conventional 148 sources, which allows much higher measurement beam intensity through small sample 149 areas. In addition to the single-spot measurements the synchrotron infrared light of 150 ANKA was used to analyze large number of overlapping spots using a step size of $2 \mu \mathrm{m}$ 151 and an aperture of $6 \mu \mathrm{m}$ diameter in a grid pattern accessed by an automated X-Y stage.

152 The geothermobarometry assessment, TWQ, is based on ion-exchange and net transfer 153 thermometers and barometers using internally consistent thermodynamic data sets by 154 multi-equilibrium calculations (Berman, 1991).

155 The Gibbs free energy minimizer PerPleX (Connolly, 2005) was applied to the 156 thermodynamic datasets in order to build the P-T pseudosection of the existing phases 157 equilibrated under the P-T conditions in the source area of the xenolith material. 


\section{Samples and analysis}

162 Our samples are typical garnet and Cr-spinel bearing lherzolites collected from the

163 Colorado plateau, where the upper mantle has been suggested to be enriched in water

164 through the effect of subduction (Humphreys et al., 2003; English et al., 2003). Olivine

165 crystals extracted from these samples are typical mantle olivine with Fo90, 3000ppm Ni

166 while Ti contents are below detection limits, also in contact with Cr-spinel inclusions.

167 The single crystals vary between 1400-2700 micrometers in size and contain visible

168 inclusions of clinopyroxene, $\mathrm{Cr}$-spinel and cracks in nm scale.

169 First, in order to determine the temperature and pressure $(P-T)$ conditions at which the

170 olivine crystals have equilibrated, geothermobarometry and silica/periclase activity

171 estimates have been performed (Berman, 1991; Berman and Aranovich, 1996). P-T

172 calculations of the olivine-orthopyroxene-clinopyroxene-garnet pairs indicate 173 equilibrium pressures of $\sim 4.8 \mathrm{GPa}$ and temperatures of $\sim 1200^{\circ} \mathrm{C}$ (indicated by the circle

174 in Fig. 1). The resulting silica activity at these P-T conditions is approximately $175 \mathrm{aSiO}_{2}=0.2$ and the periclase activity is $\sim a \mathrm{MgO}=0.16$. Following the arguments set out 176 earlier on silica undersaturated conditions, this should lead in the presence of water to a 177 detectable $\mathrm{OH}$-stretching bands between 3430 and $3630 \mathrm{~cm}^{-1}$, as indeed measured in the 178 samples (Fig. 3).

179 Second, in order to determine the phase equilibrium of the whole bulk rock chemistry

180 of the system, thermodynamic calculations have been performed using the Gibbs free 181 energy minimization code, PERPLEX (Connolly, 1995), assuming a Cr-bearing 182 peridotitic mantle composition under a wide range of $P-T$ conditions (Ehrenberg, 1982).

183 Calculations predict that the conditions derived from geothermobarometry are in a central location of a large $P-T$ equilibrium domain for the olivine-orthopyroxene- 
185 clinopyroxene-garnet-Cr-spinel pairs (Fig. 1). These results are in good agreement with 186 polarized microscopic analyses, which indicate no stress fields/shadows in the 187 surrounding olivine crystal. Both analyzed $\left(\mathrm{X}_{\mathrm{Mg}}=0.75\right)$ and calculated $\left(\mathrm{X}_{\mathrm{Mg}}=0.70-\right.$ 188 0.80) spinel compositions are similar. Therefore, the $\mathrm{Cr}$-spinel inclusions are in 189 equilibrium with the hosting olivine and their origin is cogenetic.

190 A problem in calculating the $\mathrm{OH}$ content in olivine is that during the entrainment of the 191 xenolith, within the ascending magma, the rapid decrease in pressure leads to a decrease 192 in water fugacity. We assess the extent of this problem by measuring, using synchrotron 193 based FT-IR, the core-rim variation in olivine to determine decrease or increase of OH 194 in all three crystallographic directions $(\alpha, \beta, \gamma)($ Demouchy et al., 2006). Our results 195 show an increase of $\mathrm{OH}$ from the olivine core towards the rim (Fig. 2). Analyses of the 196 rim show complexity of $\mathrm{OH}-$ fluxes restricted to the grain boundary. The hump in the 197 fast alpha grain boundary diffusion profile suggests at least two distinct pulses (Fig. 2).

198 The fact that water apparently entered the system as a grain boundary fluid is opposite 199 to the normal xenolith extraction trend, where the minerals - melt contact during 200 eruption leads to a net hydrogen loss on the grain boundaries, owing to the higher 201 solubility of water in the melt phase (Demouchy et al., 2006; Peslier and Luhr, 2006).

202 The grain boundaries of our samples record rapid, multistage, metasomatic OH203 incorporation or $\mathrm{OH}-$ loss events during or preceding the eruption; the uplift history will 204 be discussed in a forthcoming contribution.

205 Here, we focus on defects within the core of the sample, far away from the grain 206 boundaries, capturing a clear image of dynamic processes at the xenolith source region. 207 The spectra show no peaks above, $3650 \mathrm{~cm}^{-1}$, which implies the absence of hydrous 208 minerals such as serpentine, talc or other hydrous silicates (Sykes et al., 1994; Kishina et 
209 al., 2001; Kohlstedt et al., 1996). Single-spot benchtop IR measurements of olivine

210 grains show that all olivine absorbance spectra are similar to the typical olivine spectra

211 from previous studies (Bell et al., 2003; Rossman, 1996; Bell et al., 2004; Berry et al., 212 2005).

214 We first map the core of an olivine with no visible inclusions, expecting a 215 homogeneous, distribution of hydrogen by using synchrotron based FT-IR. The mapped area of $40 \times 40$ micrometer $\left(1600 \mu \mathrm{m}^{2}\right)$ has roughly the same size as the resolution of a

217 single benchtop measurement, using the Globar source of normal FT-IR equipment $218\left(1960 \mu \mathrm{m}^{2}\right)$. The average water content is $138 \pm 10 \mathrm{ppm}$ (Fig. 3), which is similar to the 219 observed water content in mantle olivine reported in previous work (Bell and Rossman, 220 1992). However, the water content is not homogenous and shows small perturbations up to 148 ppm (Fig. 3, inset). These water perturbations are smaller than the maximum resolution. They may correspond to structurally bound water in a variety of defects: 1) line defects or 2) very low angle misorientations within groups of defects including metastable hydrous phases 3) nanoscale inclusions, e.g. hydrous olivine ( $\mathrm{Mg}, \mathrm{Fe}) \mathrm{SiO}_{4} \mathrm{H}_{2}$ or Cr-spinel. Indeed, most olivine samples of the field area contain small inclusions of Cr-spinel and/or clinopyroxene forming isolated grain boundaries within the olivine single crystal (Bell and Rossman, 1992).

While the effect of line defects and groups of such defects are still below the resolution limit of the synchrotron FT-IR method, larger Cr-spinel inclusions and macroscopic cracks offer an ideal target for analysis of water content around higher dimensional

231 defect structures. In order to avoid contamination from the above described grain boundary effects, only fully embedded Cr-spinel inclusions in olivine were analyzed far 
233 away from any other grain boundaries. Inclusions within the $250 \mu \mathrm{m}$ thick, doubly

234 polished crystal wafers vary between 2-8 micrometer in size. The amount of water in 235 olivine increases dramatically upon approaching the grain boundary between olivine 236 and embedded Cr-spinel and form halos of about $40 \mu \mathrm{m}$ in diameter (Fig. 4, inset). The 237 increase of water towards the grain boundary leads also to a minor change in the olivine composition $\left(\mathrm{X}_{\mathrm{Mg}}=\sim 0.89\right)$. Although the horizontal spatial resolution of the measurement is high, we cannot avoid smearing through the focal depth of the sample.

240 The high spatial resolution of the maps therefore record spatial gradients, representing 241 local variations in water content. We record a peak of water close to the centre of the 242 Cr-spinel inclusion. The water concentration in the studied Cr-spinel inclusion is below the detection limit of the synchrotron based FT-IR and therefore any interference with

$244 \mathrm{Fe}^{2+}$ in the $\mathrm{Cr}$-spinel and the olivine can be avoided.

245 Furthermore, measurements of other sections and different focal depth shows, that the 246 water is located in the olivine crystalline lattice near the grain boundary and not within 247 the Cr-spinel grain. Away from the inclusion the typical water content is $\sim 140 \mathrm{ppm}$ 248 (Fig. 4). An area of 200-440 ppm water content is recorded up to $15 \mu \mathrm{m}$ away from the embedded water-free Cr-spinel inclusion (Fig. 4). On the inclusion itself, the water 250 content rises significantly up to values of $\sim 800 \mathrm{ppm}$. The measured hydrogen peak is 251 located on the silica dislocation/vacancy and shows the typical maximum at $3572 \mathrm{~cm}^{-1}$, which is indicative for an increase of water in olivine towards to the grain boundary 253 (Fig. 5).

254 We also analyse using optical microscopy and infrared spectroscopy totally embedded micro cracks of up to $0.4 \mathrm{~nm}$ width in olivine and record a comparable increase of water content towards an embedded micro-crack (Fig. 6). Note that the crack has a sub-micron 
257 size opening and is defined as a monomineralic grain boundary however, the water 258 content increases continuously towards the crack to reach $1000 \mathrm{ppm}$. There is no visible

259 break towards the crack. The increase of hydrogen towards the crack, and the position 260 of the hydrogen peak at $3572 \mathrm{~cm}^{-1}$, suggests that the hydrogen is incorporated in the 261 crystalline lattice of olivine and not in the crack.

\section{Implications for water in 2-dimensional defects}

264 We have presented here a new method for estimating water content in nominally anhydrous minerals, particularly applied to olivine. We have shown that for all three defect species, i.e. cracks, grain boundaries and Cr-spinel- inclusions the water content increases systematically by factor of 5-10 towards to the defect. Similarly, the defects are all surrounded by halos of water with a pattern of $\mathrm{OH}$ - point defect diffusion with increasing degree of complexity from cracks to inclusion to grain-boundary. For the case of cracks and spinel inclusion, the diffusion profiles follow the 3-D shape of the defects. The similarity of the $\mathrm{OH}$ - diffusion profiles around cracks and Cr-spinel

272 inclusions suggests that water is not structurally bound but indeed progressed through

273 point defect diffusion after microcracking of the sample, thus allowing an assessment of the timing of the damage event. While many more fluid pulses may have preceded the uplift our measurement only records a snapshot of the last pulse of the metasomatic fluid access. This last pulse has prepared conditions for the first uplift phase of the xenolith. Taking conservative estimates of equilibrium $\mathrm{OH}$-diffusion (Kohlstedt and Mackwell, 1998) the diffusion profiles can be reconciled with a residence time of less than 10 hours after access of the aqueous fluid to the source region. 
280 We can constrain the P-T conditions for water access further through the stability of

281 hydrous minerals in Fig. 1. The absence of hydrous amphibole either suggests that the 282 uplift was faster than the kinetics of amphibole formation or, that the first uplift phase 283 stalled above 36 kbar (higher than the TrTsPg stability field in Fig. 1) followed by a 284 second uplift through the hydrous Antigorite Atg stability field. The uplift path will be 285 presented in closer details in a forthcoming contribution.

286 We suggest that our results resolve the first visible snapshot of fluid transfer responsible 287 for the process of cryptic mantle metasomatism, described for similar temperature and 288 pressure conditions in many xenolith suites (Witt-Eickschen et al., 1993). Although the 289 widespread existence of cryptic enrichment of the mantle is well documented the 290 mechanism of enrichment is not fully understood. The common suggestion is that 291 access of a low viscosity, low density, fluid phase causes cryptically enriched mantle, 292 seen in its light Rare Earth Element content. Our observations suggest that the fluid is

293 transferred through both grain boundaries and intracrystalline cracks.

294 We postulate that the inhomogeneous distribution of water content also applies to larger 295 scale grain boundaries and cracks than those measured here. Water along grain 296 boundaries may have a significant influence on the damage of the mantle source region 297 possibly causing ductile/creep fracture and leading to earthquakes and eruptions 298 (Ghandi and Ashby, 1979). Another interesting aspect, which will need to be 299 investigated in future studies is the potential interaction of point and 2-dimensional 300 defect through dislocations (Heggie, 1992). Such dynamics would lead to significant 301 transport of water during solid-state deformation with important implications for metasomatism and chemical buoyancy. 
304 Acknowledgements

305 The authors appreciate Cin Ty Lee for providing the samples. We also thank Take

306 Hiraga, Steve Mackwell, Anne Peslier and all participants from the MSA workshop

3072006 (Verbania, Italy) for the fruitful and energizing discussions. We are grateful to the

308 staff of the FZK, for assistance with the Synchrotron analyses. We also thank Adalbert

309 Becker from the University of Mainz for the sample preparation. This is a contribution

310 to IGCP Project 557.

311

312

313

314

315

316

317

318

319

320

321

322

323

324 
325

326

327

328

329

330

331

332

333

334

335

336

337

338

339

340

341

342

343

344

345

346

\section{References}

Bell DR, Rossman GR (1992) Water in the Earth's mantle: The role of nominally anhydrous minerals. Science 255: 1391-1397

Bell DR, Rossman GR, Maldener J, Endisch D, Rauch, F (2003) Hydroxide in olivine: A quantitative determination of the absolute amount and calibration of the IR spectrum. J Geophys Res Solid Earth 108

Bell DR, Rossman GR, Moore RO (2004) Abundance and partitioning of OH in a highpressure magmatic system: Megacrysts from the Monastery kimberlite, South Africa. J Petrol 45: 1539-1564

Berman R (1991) Thermobarometry using multi-equilibrium calculations - a new technique, with petrological applications. Can Mineral 29: 328-344

Berman RG, Aranovich LY (1996) Optimized standard state and solution properties of minerals.1. Model calibration for olivine, orthpyroxene, cordierite, garnet, ilmenite in the system $\mathrm{FeO}-\mathrm{MgO}-\mathrm{CaO}-\mathrm{Al}_{2} \mathrm{O}_{3}-\mathrm{TiO}_{2}-\mathrm{SiO}_{2}$. Contrib Mineral Petrol 126: 1-24

Berry AJ, Hermann J, O'Neill HSC, Foran GJ (2005) Fingerprinting the water site in mantle olivine. Geology 33: 869-873

Connolly JAD (2005) Computation of phase equilibria by linear programming: A tool for geodynamic modeling and its application to subduction zone decarbonation. Earth Planet Sci Letters 236: 524-541

Demouchy S, Jacobsen SD, Gaillard F, Stern CR (2006) Rapid magma ascent recorded by water diffusion profiles in olivine. Geology 34: 429-432 
347 Ehrenberg SN (1982) Petrogenesis of garnet lherzolithes and megacrystalline nodules from the Thumb, Navajo Volcanic Field. J Petrol 23: 507-547

English JM, Johnston ST, Wang K (2003) Thermal modelling of the Laramide orogeny: testing the flat-slab subduction hypothesis: Earth Planet Sci Letters 214: 619-632

Ghandi C, Ashby MF (1979) Overview no. 5 Fracture-mechanism maps for materials which cleave: F.C.C., B.C.C. and H.C.P. metals and ceramics. Acta Metal 27: 1565-1602

Griggs DT (1967) Hydrolytic weakening of quartz and other silicates. Geo J Royal Astro Soc 14: 19-32

Heggie M (1992) A molecular water pump in quartz dislocations. Nature 355: 337-339.

Hiraga T, Anderson IM, Kohlstedt DL (2004) Grain boundaries as reservoirs of incompatible elements in the Earth's mantle. Nature 427: 699-703

Hirth $G$, Kohlstedt DL (1996) Water in the oceanic upper mantle: implications for rheology, melt extraction and the evolution of the lithosphere. Earth Planet Sci Letters 144: 93-108

Humphreys ED, Hessler E, Dueker KG, Farmer GL, Erslev EA, Atwater T (2003) How Laramide-age hydration of North American lithosphere by the Farallon slab

Khisina NR, Wirth R, Andrut M, Ukhanov AV (2001) Extrinsic and intrinsic mode of hydrogen occurrence in natural olivines: FTIR and TEM investigation. Phys Chem Minerals 28: 291-301 
369 Khisina NR, Wirth $R$ (2002) Hydrous olivine (Mg,Fe) $)_{2-\mathrm{x}} \mathrm{n}_{\mathrm{x}} \mathrm{SiO}_{4} \mathrm{H}_{2 \mathrm{x}}$ - a new DHMS phase

370

371

372

373

374

375

376

377

378

379

380

381

382

383

384

385

386

387

388

389

390

391

of variable composition observed as nanometer-sized precipitations in mantle olivine. Phys Chem Minerals 29: 98-111

Kohlstedt DL, Keppler H, Rubie DC (1996) Solubility of water in the polymorphs of $(\mathrm{Mg}, \mathrm{Fe})_{2} \mathrm{SIO}_{4}$. Contrib Mineral Petrol 123: 345-357

Kohlstedt DL, Mackwell SJ (1998) Diffusion of hydrogen and intrinsic point defects in olivine. Zeitschrift Fur Physikalische Chemie-International Journal of Research in Physical Chemistry and Chemical Physics 207: 147-162.

Matveev S, Portnyagin M, Ballhaus C, Brooker R, Geiger CA (2005) FTIR spectrum of phenocryst olivine as an indicator of silica saturation in magmas. J Petrol 46: 603-614

Nakamura A, Schmalzried H (1983) On the nonstoichiometry and point defects of olivine. Phys Chem Min 10: 27-37

Peslier AH, Luhr JF (2006) Hydrogen loss from olivines in mantle xenoliths from Simcoe (USA) and Mexico: Mafic alkalic magma ascent rates and water budget of the sub-continental lithosphere. Earth Planet Sci Letters 242: 302-319

Regenauer-Lieb K, Yuen D, Branlund J (2001) The Initation of Subduction: Criticality by Addition of water? Science 294: 578-580

Regenauer-Lieb K (2006) Water and Geodynamics. Rev Mineral Geochem 62: 451-473 Regenauer-Lieb K, Kohl T (2003) Water solubility and diffusivity in olivine: Its role for planetary tectonics. Mineral Mag 67: 697-715

Rossman GR (1996) Studies of $\mathrm{OH}$ in nominally anhydrous minerals. Phys Chem Min 23: $299-304$ 
392 Sykes D, Rossman GR, Veblen DR, Grew ES (1994) Enhanced H And F Incorporation 393 In Borian Olivine. Am Mineral 79: 904-908

394 Wright K, Catlow CRA (1994) A computer simulation study of (OH) defects in olivine. 395 Phys Chem Min 20: 515

396 Witt-Eickschen G, Seck HA, Reys C (1993) Multiple enrichment processes and their relationships in the subcrustal lithosphere beneath the Eifel (Germany). J Petrol 398 34: $1-22$.

399

400

401

402

403

404

405

406

407

408

409

410

411

412 


\section{$414 \quad$ Figure captions}

415 Figure 1: Phase equilibria computed for ultramafic bulk composition. Mineral

416 abbreviations are: O, olivine; Opx, orthopyroxene; Cpx, clinopyroxene; Gt, garnet;

417 CrSp, Cr-spinel; esk, eskolite; knorr, knorringite; ab, albite; Atg, antigorite; A-phase, a418 phase; Chl, chlorite; B, brucite; TrTsPg, amphibole. The computations account for the 419 oxides: $\mathrm{SiO}_{2}, \mathrm{Al}_{2} \mathrm{O}_{3}, \mathrm{Cr}_{2} \mathrm{O}_{3}, \mathrm{FeO}, \mathrm{MgO}, \mathrm{CaO}, \mathrm{Na}_{2} \mathrm{O}, \mathrm{H}_{2} \mathrm{O}$. The shading shows the 420 variance of the different phase fields. The stability field of Gt-CrSp-O-Opx-Cpx is 421 stippled.

423 Figure 2: Core rim relationship in olivine shows the increase of $H$ in all three 424 crystallographic directions $(\alpha, \beta, \gamma)$.Our results shows an increase of $H$ from olivine 425 core towards to the rim. These indicates an addition of $H$ during the eruption (rim) and 426 give the amount (core) of $H$ added to the cyrstall in the mantle.

Figure 3: Single measurenments of olivine grains. The FT-IR spectra were produced using a synchrotron and show the $\mathrm{OH}$ vibration stretching bands in $\alpha, \beta, \gamma$ directions for 430 the studied olivine sample HS1. The local resolution is 2 micron. The sample was normalized to $1 \mathrm{~cm}$ thickness and the calculated water content normalized in ppm $\mathrm{H}_{2} \mathrm{O}$ by weight is 138 by using Beer-Lambert law. Inset shows the 3D-map of the same optical inclusion free area of olivine crystal HS1, 40 x 40 micron in size. The water content is $\sim 140 \mathrm{ppm}_{2} \mathrm{O}$ by weight (blue). 
437 Figure 4: 2D and 3D maps of $\mathrm{H}_{2} \mathrm{O}$ content increasing towards a totally embedded Cr438 spinel inclusion in olivine (sample HS1). The Cr-spinel inclusion varies in size between 439 5-8 micron (white area). The $\mathrm{H}_{2} \mathrm{O}$ content increases towards the Cr-spinel inclusion 440 significantly up to values of about $800 \mathrm{ppm}$.

442 Figure 5: The measured hydrogen peak is located on the silica vacancy and shows the 443 typical peak at $3572 \mathrm{~cm}^{-1}$.

445 Figure 6: We assess the effect of $2 \mathrm{D}$ defects on water content within olivine through 446 mapping totally embedded micro cracks in olivine (sample HS1). The continuous 447 increase of $\mathrm{OH}$ concentration towards an embedded micro crack is clearly seen. Note, 448 that the crack itself has sub-nanometre scale opening. It is thus invisible for FT-IR 449 measurements. Since we detect an increase in $\mathrm{OH}$-concentration up $15 \mu \mathrm{m}$ away from 450 the crack we conclude that the water is located in point defects around the crack and not 451 within the crack itself.

453 Authors addresses: Dr. H. Sommer, Department of Geology, University of Botswana, 454 Private Bag 0022, Gaborone, Botswana email: info@holgersommer.de. Prof. Dr. K. 455 Regenauer-Lieb, School of Earth \& Geographical Sciences, The University of Western 456 Australia, Perth, Western Australia 6009, Australia. Dr. B. Gasharova, ANKA/Inst. 457 Synchotron Radiation, Forschungszentrum Karlsruhe GmbH, Hermann-von-Helmholtz458 Platz 1, Eggenstein-Leopoldshafen, D-76344 Germany. Dr. D. Siret, CSIRO 459 Exploration \& Mining, PO Box 1130, Bentley, WA 6102, Australia. 


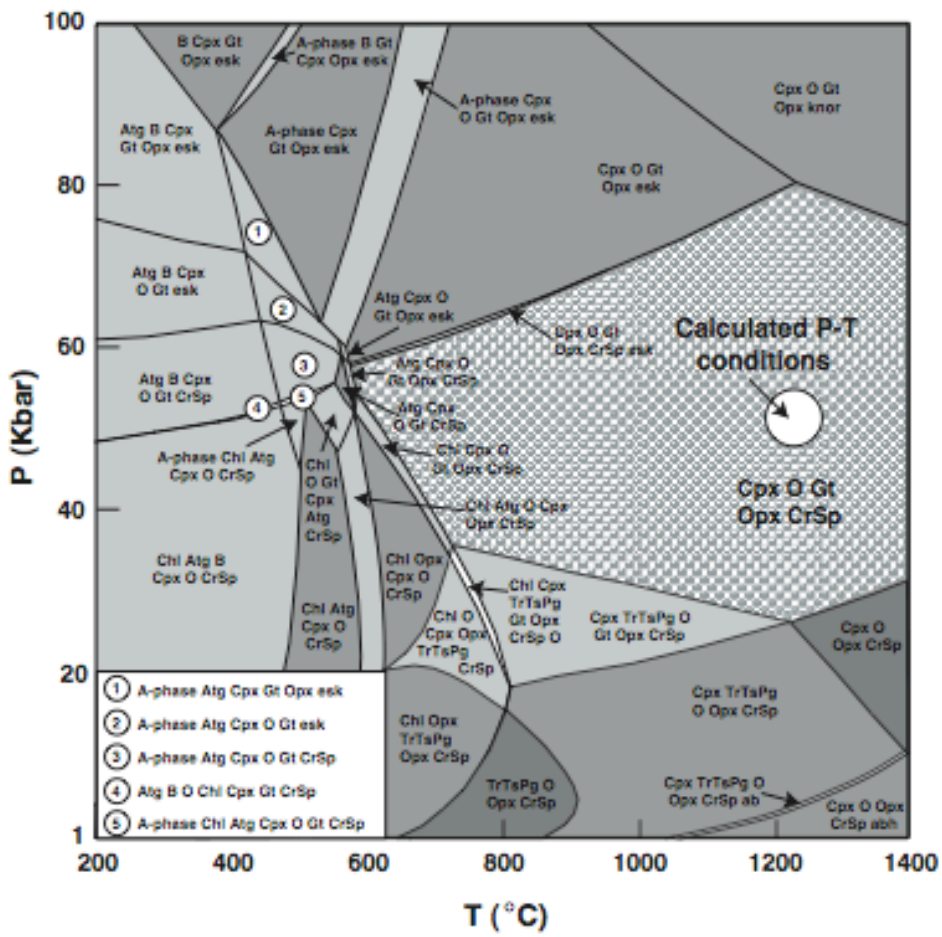

Figure 1 


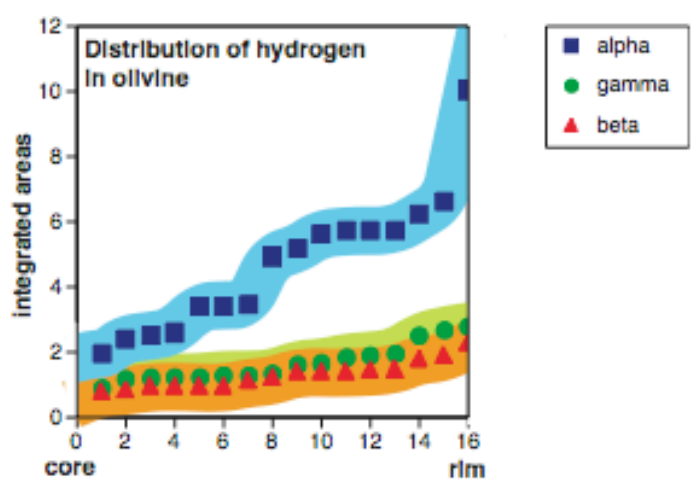

Figure 2 


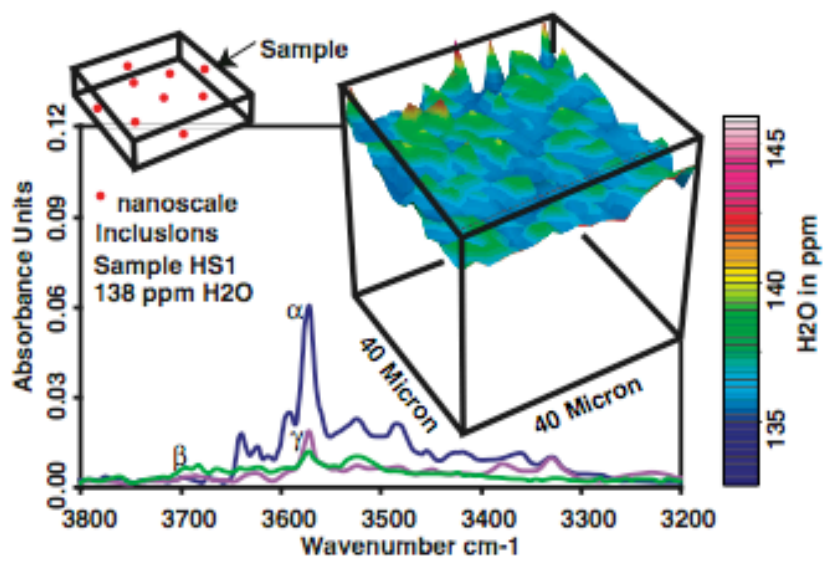

Figure 3 


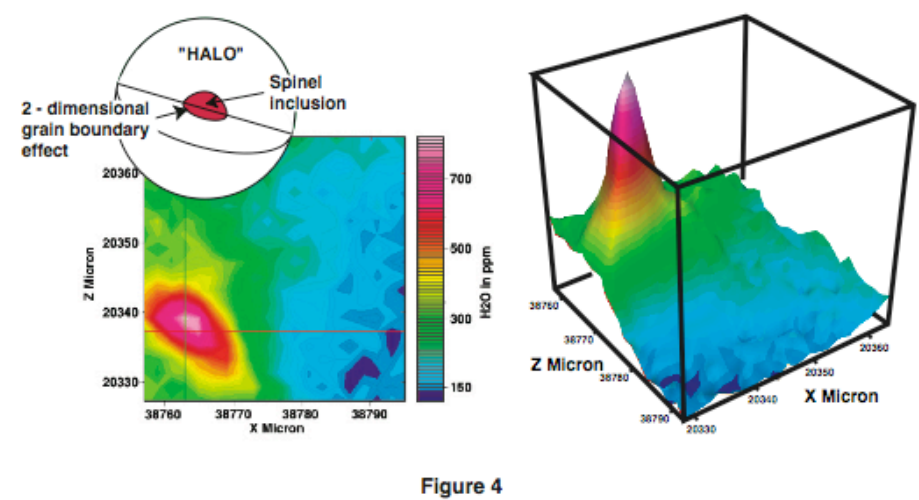




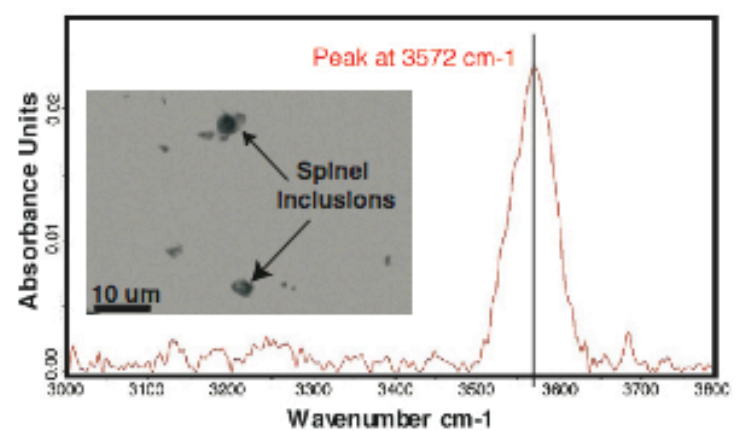

Figure 5 


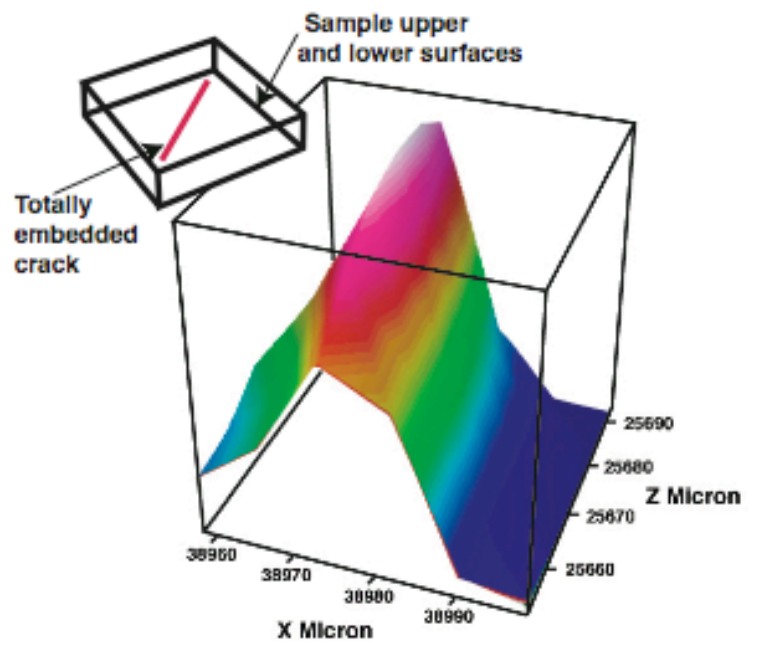

Figure 6 